\title{
Vegetation Composition and Deforestation Impact in Gambella National Park, Ethiopia
}

\author{
Abreham Berta Aneseyee \\ Department of Natural Resource Management, College of Agriculture and Natural Resource, Wolkite University, Wolkite, Ethiopia \\ Email address: \\ abresh1240@gmail.com, abreham.berta@wku.edu.et

\section{To cite this article:} \\ Abreham Berta Aneseyee. Vegetation Composition and Deforestation Impact in Gambella National Park, Ethiopia. Journal of Energy and \\ Natural Resources. Vol. 5, No. 3, 2016, pp. 30-36. doi: 10.11648/j.jenr.20160503.11
}

Received: March 13, 2016; Accepted: March 21, 2016; Published: June 30, 2016

\begin{abstract}
The vegetation of Gambella national park varies in terms of composition and structure due to the occurrence of rivers bisect the park. Data of the vegetation was collected by different techniques such as field observation, GIS and remote sensing, GPS and compass, and topographic map. The scientific name, local name and their uses was identify by indigenous knowledge of the community, experts knowledge and field guide line book for each tree species. Stratification was used of homogeneity/heterogeneity of the land use of the park and make easy ways for study. There were also 80 sample plots with $10 \mathrm{~m} \times 10 \mathrm{~m}$ rectangular plot size was taken to carry out counting and identifying the species using transect line in the study area. A total of 39 species were recorded and the most dominance species was Grewia mollis. The analysis indicated that the riverine forest was dense (more stems) than terrestrials forest. The highest stem grown in the Riverine forest was Grewia mollis A. Juss whereas terrestrial species was Bridelias cleroneura and also more tree species were available in terrestrial wood land forest than riverine forest. As move to the reverine forest, there was more vegetation, abundance, distribution and greenness. Land use land cover change indicated that terrestrial wood land forest is decreasing from time to time due to anthropogenic factors. Therefore, in order to keep the sustainability of the national park from deforestation there must be integration of stack holder organization, awareness creation of the community, participatory approach in the park is required.
\end{abstract}

Keywords: Vegetation, Park, Deforestation, Composition

\section{Introduction}

The natural environment in Gambella regional state is currently suffering very seriously and wide spread damage, and, since this is the case species of plant and wild animal including complete ecosystems is disappearing at an alarming rate [1]. As deforestation is increasing, it reduces the quality of the Regional population, specially the poor, who are living close to the forest land. According to [2] deforestation increases then occurrence of higher volume run off which can result in flooding in low plain areas.

The marginal land around the park is occupied by increasing human population. The increasing population leads to increasing demand for agricultural land and forest products, thus forcing the people to clear woodland/ natural forest for settlement and expansion of farmland. A total of 140,000 ha of natural forests (mainly woodland) were cleared for resettlement purpose [3]. According to [4], 437,500 hectares of woodland are made available for investments into commercial agriculture.

Currently, the park is shrinking and over exploiting due to investment expansion, fuel wood finding, new grass rejuvenate for animal feeding etc so that it need proper management plan for tourist attraction and economic contribution to the region and the country. From this research it is recommended as solution for avoiding deforestation and exploiting of the national park such as providing alternative energy source, awareness creation of local community and implementing the policy.

The objectives study was differentiate dominant tree species, composition, type and structure of forest in the national park; Observe the extent of deforestation based on land use land cover change and identify the most reverine and land race species tree in the national park. 


\section{Methods and Materials}

\subsection{Description of the Study}

This study was conducted in Agnwalk zone, Gambella National Regional State, in the Gambella national park and located at $850 \mathrm{~km}$ west of Addis. Its Coordinates is $34^{\circ} 0.00^{\prime}$ East $7^{\circ} 52.00^{\prime}$ North. The park area is home to the Nuer and the Anuak people and it is said to be "a land of least disturbed and intact ecosystem" as compare to other part of the National Parks of the country. The climate of the region comes under the influence of the tropical monsoon from the Indian Ocean, characterized with high rainfall in the wet period from May to October and dry period from November to April which is recorded highest temperature as shown in below figure 1. Agro-climatically, it is classified as Kolla and the climate is hot and humid High temperatures are recorded just before the onset of rains in May. Annual mean temperature is with a minimum and maximum of $18.09^{\circ} \mathrm{C}$ and $39.34^{\circ} \mathrm{C}$ respectively. The lowest rain fall is recorded in November to April whereas highest rainfall is May to October. Annual rainfall is estimated to around $69.7 \mathrm{~mm}$ in the plains. Landscape of Gambella national park is low and flat with altitude ranging from 379 to $507 \mathrm{~m}$ asl. This is the lowest altitude in the region. The average altitude is around $443 \mathrm{~m}$ asl.

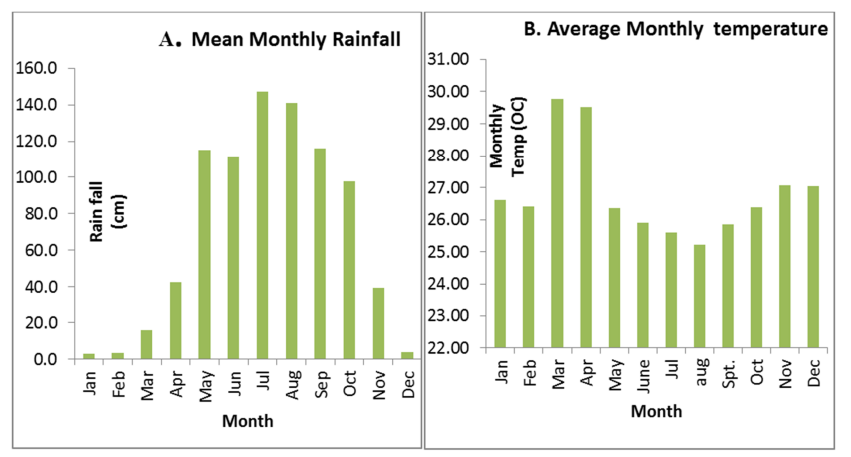

Fig. 1. Climatic characteristic of the study area.

\subsection{Sampling Design}

A transect is a line along which samples of vegetation are taken. It is set up deliberately across areas where there are rapid changes in vegetation and marked environmental gradients [5]. If some parts of the strata have higher vegetation than others, systematic selection usually results in greater precision than random selection. Systematic sampling also may appear more credible [6].

Sampling sites from the forest was arranged by the line transects from the starting of forest to all directions covering the whole range of the area $(20 \mathrm{~m}$ right and left of the river) that encompass for the study. Transect line was made along the riverine forest and wood land forest/land forest using the GPS navigation system. A plot of $10 \times 20 \mathrm{~m}\left(200 \mathrm{~m}^{2}\right)$ was placed at $200 \mathrm{~m}$ distance drop between each plot because the environmental variables were similar in the study area. The number of plots (number of plot reverine vegetation was 40 plots and terrestrial wood land forest/ land forest was 40 plots), totally 80 samples/plots were taken. To collect riverine forest data, there was $20 \mathrm{~m}$ to the right and left from the tip of the river followed all the trees measuring and the necessary data collection.

A complete list of trees by classified them reverine and wood land forest/ forest land/ in each plot was done. Plant specimens were collected, pressed, dried and identified their scientific name, species and vernacular name in the Gambella National park. During collecting plant and vegetation data, Local people (Anywaa, Nuer) were involved, and asked the local names and the uses of the plants encountered in the survey. The botanic names of the plants were identified using [7] manual which is located in the Gambella National Park Office. The other method to identify the vegetation or tree name is using monograph and hand books.

Concerning deforestation impact observation, three year dates (1990, 2000 and 2010) of LANDSAT satellite images were acquired from different. The sensor was LANDSAT ETM with path 171 rows $54 \& 55$, path 172 rows $54 \& 55$. The band is 7 with pixel size/ Ground Resolution (m) of $30 \mathrm{~m}$. Supervised image classification was a method for the study area by gathering appropriate data such as GPS which were representative of each desired land cover category. Assessment of the accuracy was done based on the data that collected in the field work.

\subsection{Determination of Vegetation Composition and Analysis}

Vegetation composition is determined using Species Richness, Diversity and Simpson's diversity index. Simpson's Diversity Index is a measure of diversity which takes into account both richness and evenness. It can be determined using in the following formula

$$
D=\sum \frac{\mathrm{n}(\mathrm{n}-1)}{\mathrm{N}(\mathrm{N}-1)} \text { or } D=\sum(\mathrm{n} / \mathrm{N})^{2}
$$

$\mathrm{n}=$ the total number of organisms of a particular species $\mathrm{N}=$ the total number of organisms of all species

Once the data collection is completed, recording and organizing on the excel data sheet and SPSS software version 21 , analyze and interpret based on the result. The relationship between each forest stratum was tested by linear regression, paired $t$ test, correlation and descriptive statistics. Statistical mean differences were considered significant at 0.05 .

\section{Result and Discussion}

\subsection{Tree Species Composition in the National Park}

In the study area recorded a total of 39 species. The total stem number was 3104 and the most dominance species was Grewia mollis (186 stem). The second dominance tree species was Diospyros abyssinica (140 stem) in the study area. The least dominance species were Bridelia scleroneura (56 stem), Olyral atifolia (55 stem), Diospyros mespiliformis (53 stem), Cordia gharaf (50 stem) and Ficussycomoros 46 stem) respectively (see Appendix 1). 


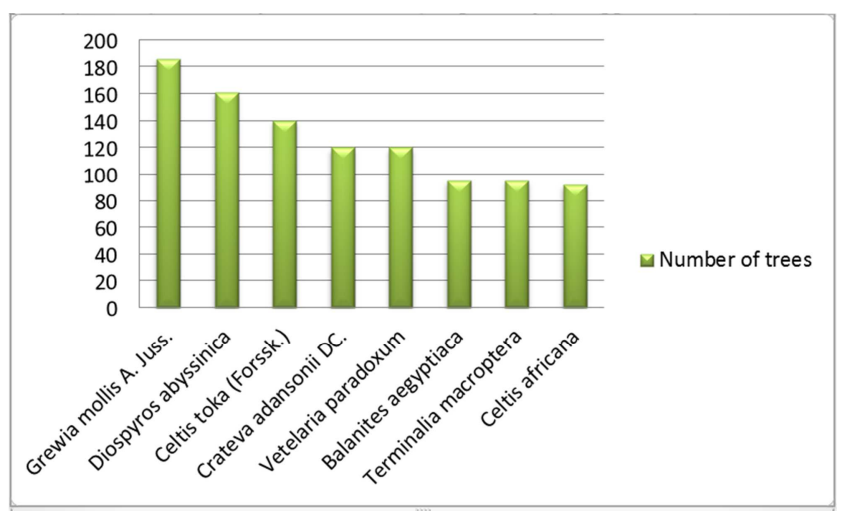

Fig. 2. The highest 9 number of tree species.

The plot analysis indicated that the riverine forest is dense (more stems) than terrestrials forest and the tree occurred in the study area was 1262 tree/ha.

The frequency and frequency percent distribution of species showed that Balanites aegyptiaca 86 (11.24\%), Pterocarpus lucens 83 (10.85\%) \& Gardenia ternifolia 67 $(8.76 \%)$ were the most tree species frequently occurred, respectively. The species with the least occurrence in the study site were Acacia hockii, its frequency was $3(0.39 \%)$, Cordia africana, Ziziphus mucronata and Ficus sycomoros their frequency was $2(0.26 \%)$ for each of them respectively. (See appendix 1).

\subsection{DBH and Height Distribution of the Trees}

The result indicated that, as DBH of the tree is increased the density of the tree is decreased. In general, 31 to $45 \mathrm{~cm}$ $\mathrm{DBH}$ class was found to be dominant species and $\leq 15 \mathrm{~cm}$ was the second dominant DBH class (the second highest density). Whereas $\geq 76 \mathrm{~cm} \mathrm{DBH}$ was the lowest density tree species (see fig. 3). The DBH of two forest stratum sites, the riverine forest average $\mathrm{DBH}$ and height $10.81 \mathrm{~m}$ and 37.17 $\mathrm{cm}$ respectively, the forest land/wood land/ average $\mathrm{DBH}$ and height was $9.32 \mathrm{~m}$ and $36.16 \mathrm{~cm}$ respectively. Therefore, the tree species occurred at riverine forest higher $\mathrm{DBH}$ than forest/wood land/.

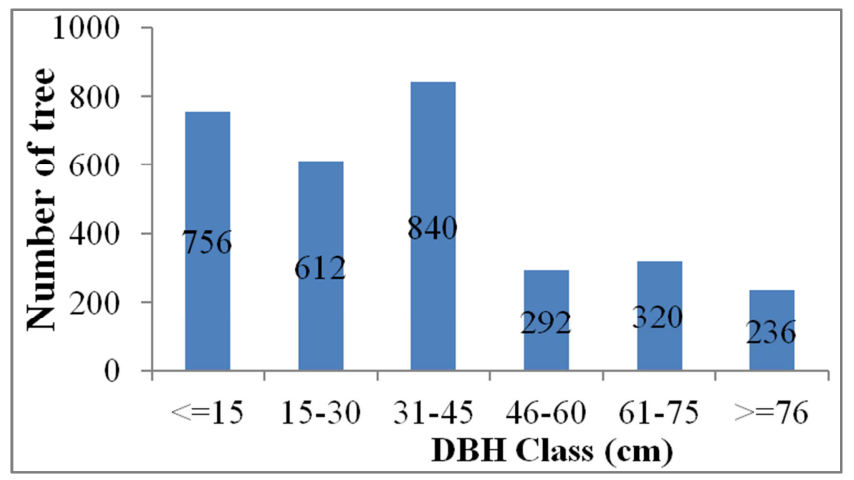

Fig. 3. Number of tree with DBH class distribution.

The tree species that identified in the study site indicated different DBH class. Grewia mollisis the highest average DBH value with $41.34 \mathrm{~cm}$ was recorded in the study site following Crateva adansonii with average DBH of $40.75 \mathrm{~cm}$. Diospyros abyssinica, Terminalia macroptera, Balanites aegyptiaca. Acaciaseyal and Gardenia ternifolia shown the mean DBH of $40 \mathrm{~cm}$ for each tree species.

Height of the tree in the study site indicated that species such as Olyral atifoliawas found the highest height distribution and its height is $14 \mathrm{~cm}$. Balanites aegyptiaca was second highest height distribution and its height is $13.50 \mathrm{~m}$. Pennisetum polystachionis the third height which is $12 \mathrm{~cm}$. and they are found in the higher height classes dominating the upper canopy. The lower part of the forest is mainly covered by shrubs, bushes and small trees their DBH is less than $5 \mathrm{~cm}$. The result obtained from this study indicated that the highest species density was found in the lower height classes. The analysis of tree height of the study site based on number of tree isresulted in the overall decreasing trend with an increase in height. As shown in Figure 4 below, the number of trees in the height class $\leq 8 \mathrm{~m}$ was higher followed by $8-10 \mathrm{~m}, 10-12 \mathrm{~m}$ and $14-16 \mathrm{~m}$. Therefore, the height class with the height of $\leq 8 \mathrm{~m}$ contained the highest number of individual trees which is found to be 542 /ha (27\%). The least number of trees were recorded in height greater than $\geq 16$ and found to be $89 /$ ha which is $4 \%$. The remaining percentage of the tree is found in height class of $8-10 \mathrm{~m}, 10-13 \mathrm{~m}$ and $13-$ $16 \mathrm{~m}$ and their percentage $26 \%, 24 \%$ and $18 \%$ respectively.

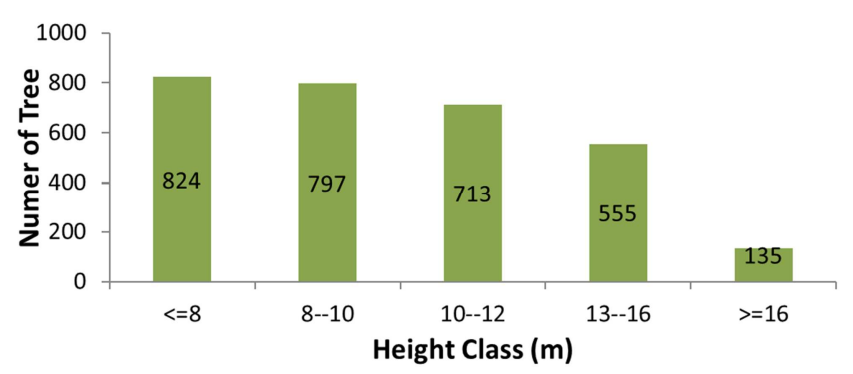

Fig. 4. Show the number of tree species classified by height.

\subsection{Vegetation Composition in Reverine Forest and Terrestrial Wood Land Forest}

In order to obtained the total vegetation density in the study area, there was summing the two forest stratum the forest species. The study indicated that there was variation of vegetation composition in the riverine and wood/land forest. As move to the reverine forest, there was more vegetation, abundance, distribution and greenness but the species number was higher in the terrestrial wood land forest than reverine forest.

The highest stem grown in the Riverine forest were Grewia mollis A. Juss. (186 stem/ha), Diospyros abyssinica (161 stem/ha) and Celtisa fricana (stem 140/ha) where as highest stem wood land forest species were Bridelia scleroneura (108 stem), Stereosper mumkun thianum (102 stem) and Gardenia ternifolia (98 stem) respectively. The result In the study area indicated that more tree species were available in the wood land forest and its number of species in wood land forest was 22 where as reverine forest species number was 16 species but there were tree species occurred 
in both forest stratum (reverine and wood land forest) such as Cordia africana Lam., Cordia africana Lam., Balanites aegyptiaca, Grewia mollis, Balanites aegyptiaca and Terminalia macroptera.

Simon and diversity index for reverine indicated 0.4 and the terrestrial forest is 0.7 . The result indicated that more species occurrence in the terrestrial forest land.

\subsection{Species Evenness and Richness in the Forest Stratum}

It is very important calculating Simpson's Index to know Species evenness and richness based on sampled the species present in the study area and the total sampled species as shown below table 1. Generally there were species occurrence higher in the terrestrial forest (22) than reverine forest (16) and there were also four species occurred in both reverine and terrestrial forest.

Table 1. The species occurrences in the reverine and terrestrial forest of the National Park

\begin{tabular}{llll}
\hline No & Stratum & No (N) Species & N (n-1) \\
\hline 1 & Reverine & 16 & 240 \\
2 & Terrestrial Forest & 22 & 461 \\
3 & Both & 4 & 12 \\
& Total (N) & 42 & 713 \\
\hline
\end{tabular}

Calculate Simpson's Index value was indicated as below

Sum of $\mathrm{n}(\mathrm{n}-1)=713$

$\mathrm{N}=42, \mathrm{D}=713 / 42 * 41=0.4$ (Simpson's Index)

$\mathrm{D}=0.4$ (Simpson's Index)

Simpson's Index of Diversity 1 - D = 0.6

The value of Simpson's index also ranges between 0 and 1 , the greater the value, the greater the sample diversity. Therefore, the result indicated that there is high diversity of species of tree in the National Park.

\subsection{Land Use Land Cover Change (LULCC) of Gambella National Park}

There was a remarkable decrease of forest land from $43.56 \%$ to $31.53 \%$ which was reduced by 53,027 ha $(12.03 \%)$ in 2000 and also the study indicated that there was decreasing in wood land from $39,372.3$ ha to $32,450.18$ ha $(1.58 \%)$ within 10 years. Generally there was decreasing of forest land, wood land and shrub land while grass land (grazing land + crop land), bare land and shrub land was increased.

Between 2000 and 2010, there was decreasing of forest land from 137,858 ha to 84,552 ha which was 53,306 ha $(12.19 \%)$ in the previous 10 years. There was also reduction of wood land by $(7,424.18$ ha) $1.70 \%$. However, grass land, bare land and water body were increased by $11.86 \%, 1.57 \%$ and $0.46 \%$ respectively. Therefore, forest wood, land and water body portion of the study area was converted to grass land, shrub land and bare land within 10 years due to anthropogenic factors such as expansion of agriculture, overgrazing, fuel wood finding etc and small change in water body which was 6.01 ha.

The result indicated that almost 105,924 ha area of the forest has gone away in last 20 years (between1990-2010) which was about $24.22 \%$ lost. The other land use which has decreased was woodland and the estimated lost about $14,346.30(3.28 \%)$ in 20 years period and the water body also decreased by 200.22 ha $(0.05 \%)$. In principle, the LU/LC decreased in a certain time has to go to other LU/LC and results increment of other LU/LC. Therefore, on the contrary shrub land, grass land and bare land have increased about $27.55 \%$ at the expense of the forestland, wood land water body has decreased about $27.55 \%$ between 1990 to 2010 .

Table 2 shows the rate of changes in land use and land cover classes of forest land between the years 1990 and 2010 had been reduced by an annual rate of about 8,827 ha/year which was $2 \%$ lost each years. The wood land annual loss between 1990-2010 continued to decline rapidly at a rate of $1,195 \mathrm{ha} /$ year $(0.27 \%)$. The total increment of grass land was $24.38 \%$ and its annual increment was $2.03 \%$ and also the total increment of shrub land, bare land was $2.24 \%$ and $0.93 \%$ respectively in the National Park. The total losses of forest land and wood land were high in the National Park due to expansion of agriculture, fuel wood finding, and pole for construction. Generally, the exploitation forest and wood land is high then results converting forest land and wood land in to grass land, bare land and shrub land. In the study area the land use land cover change indicated that unless good management plan is implemented the vegetation composition of the National Park is still declining.

Table 2. The rate of LULCC for 20 years of Gambella National Park.

\begin{tabular}{lll}
\hline Land use land cover & LULCC 1990-2010 (ha) & Change in \% \\
\hline Forest & $-105,924.00$ & -24.22 \\
Grassland & $106,608.00$ & 24.38 \\
Woodland & $-14,346.30$ & -3.28 \\
Shrub land & $9,786.90$ & 2.24 \\
Bare land & $4,075.70$ & 0.93 \\
Water body & -200.22 & -0.05 \\
Total & 437282 & \\
\hline
\end{tabular}

\section{Discussion}

The riparian habitat (riverine forest) is characterized with specific microclimate and soil conditions of higher humidity and is influenced by near surface groundwater dynamics [8]. There are rivers that cross the national park and forests following the line of the river in the national park. Wambabya riverine forests system in Uganda provides clear saleable environmental services and therefore, a potential for developing environmental rewards schemes. There are clear and marketable environmental services such as carbon sequestration, watershed and biodiversity services but are under threat of degradation, with the major drivers being agriculture and tree cutting for timber. The services can be quantified [9]. Similar trend with Wambabya riverine forests system in Uganda, Gambella National Park has different vegetation types which provide for different ecosystem services.

The trees grow rapidly in riparian zones due to favorable moisture and nutrient conditions. The riverine Forests are found along the major streams and rivers and the characteristic woody plant species are Celtis africana, 
Tamaridus indica, Mimusops kummel, Syzigium guineense. Other common species included are Cordia Africana, and Teclea nobilis [10]. The riverine forest along the Baro river Gambella includes the following species Baphia abyssinica, Celtistoka, Lecaniodiscus fraxinifolius, Lepisan thessenegalensis, Malacntha alnifilia, Mallotus sp., Tapura fischeri, Trichiliaretusta and Ziziphus pubescens [11]. The species found in the study area was Cratevaadansonii, Tamarindus indica, Celtis Africana, Cordia Africana, Tapura fischeri, Ziziphus pubescens.

The land use/cover types Gambella region \& Gambella wordeda is relatively similar land cover units i.e. the dominant land use category is wood land, followed by grass land, bush land, forest land, agriculture land and bare land [12]. The study result show that the dominant land use classes in the national park was grass land, forest land, shrub land, bare land, wood land and water body respectively. Grass land is dominant land use land cover in the National Park and this grass is important for conservation biodiversity as feeding for wild animals but it is dry during high temperature season then wild animals become lost their feeding and distributed follows move to Boma national park, Sudan. Analysis the forest and wood land coverage of the national park was reduced due to reduction forest and wood land in the last 20 years. Despite the protection guaranteed to National Parks in the most recent Wildlife Proclamation, expansion threatens part of Gambella National Park, and permanent human settlements in Bale Mountains, Awash, Simien Mountains, and Abijata Shala National Parks increasingly upset the ecosystem. Preservation of Ethiopia's biodiversity of species and ecosystems is vital to ensure sustainable growth, to mitigate the effects of climate change and to avoid the collapse of life support systems [13]. The management and conservation activities of the park is mainly by EWCA branch of Gambella office and Gambella National Park office is in center Gambella town as the result it is not easily accessible to manage the park. The distance between the park office and the conservation area is more than $20 \mathrm{~km}$ and this makes difficult for management of the park. As much as possible the office is in or around the park. It should not be far distance between the office and the conservation area to avoid deforestation.

The environmental services in Wambabya riverine forests system in Uganda are faced with challenges of land use practices which have greatly contributed to their degradation. This is due to expanding population pressure which calls for more agricultural production, and also the need for money through cutting of trees for timber [9]. The trend show in Gambella national park that, land use competition among land use cover; forest land, wood land and water body, one can observe a considerable decreasing in the last 20 years due to expansion of agriculture and deforestation for energy supply.

\section{Conclusion}

The study suggests that there are different species occurring and composition in Gambella National Park which makes it best for providing of different ecosystem services. There are different species diversity occurred in the Gambella National Park which makes it best for conservation of biodiversity. The most dominance species was Grewiamollis, Diospyros abyssinica, Celtis toka, Crateva adansonii and Vetelaria paradoxum. The study shows that the higher DBH class, the lower the density of the tree and the forest was mostly dominated by small sized trees. The forest stratum of the study area vegetation composition varied as a result move toward to riverine forest, more vegetation with higher $\mathrm{DBH}$ and height was available than terrestrials forest even if more species was presented in the terrestrial forest than riverine forest. The diversity index indicated that 0.6 then there is higher species composition of species in the national park. The land use land cover change in the national park conclude that forest land, wood land and water body were considerable decreasing by $27.64 \%$ in the last 20 years whereas grass land, bare land and bush/shrub land were increased by $27.55 \%$. Form this concluded that the main reason for conversion of forest land into grass land was expansion of agriculture, fuel wood finding, pole for house construction.

\section{Recommendation}

The research result of existing forests of the national park was dominated by small sized trees. Therefore, even if the park is conserved, protecting it from deforestation fully from human interference is necessary to continue the ecosystem services.

Land use and land cover change analysis is a good indicator of the trend of their dynamics. Therefore, socioeconomic data of the area is necessary to increase efficiency and accuracy to use the result of the analysis for decision making.

Since, the vegetation type in Gamebella National Park is diverse in structure, composition and species then choice of conservation for each vegetation species type is required. Federal government the regional government, local and Non government should made fundamental thinking in the policy of national park management ensuring the sustainability of the park.

It is the fact that there is scarcity of data on vegetation characteristics and types in the national park/protected areas. Therefore, there is a need more research in the national park with comparing others national park of Ethiopia. Strong attention need to be given for the conservation of multipurpose tree species such as cordia Africana, Vetelaria paradoxum and otersin the national park in order to conserved from deforestation. Awareness creation and participatory approach is necessary to the local communities. The society settled around the park does not understand the role of the national park for environmental, economic and cultural value to the region and the country. Environmental education program should be given to the community continually to protect the forest from deforestation. 


\section{Appendices}

Appendix 1 Tree species, mean DBH and height, frequency, relative frequency, density/ha and relative density of the species

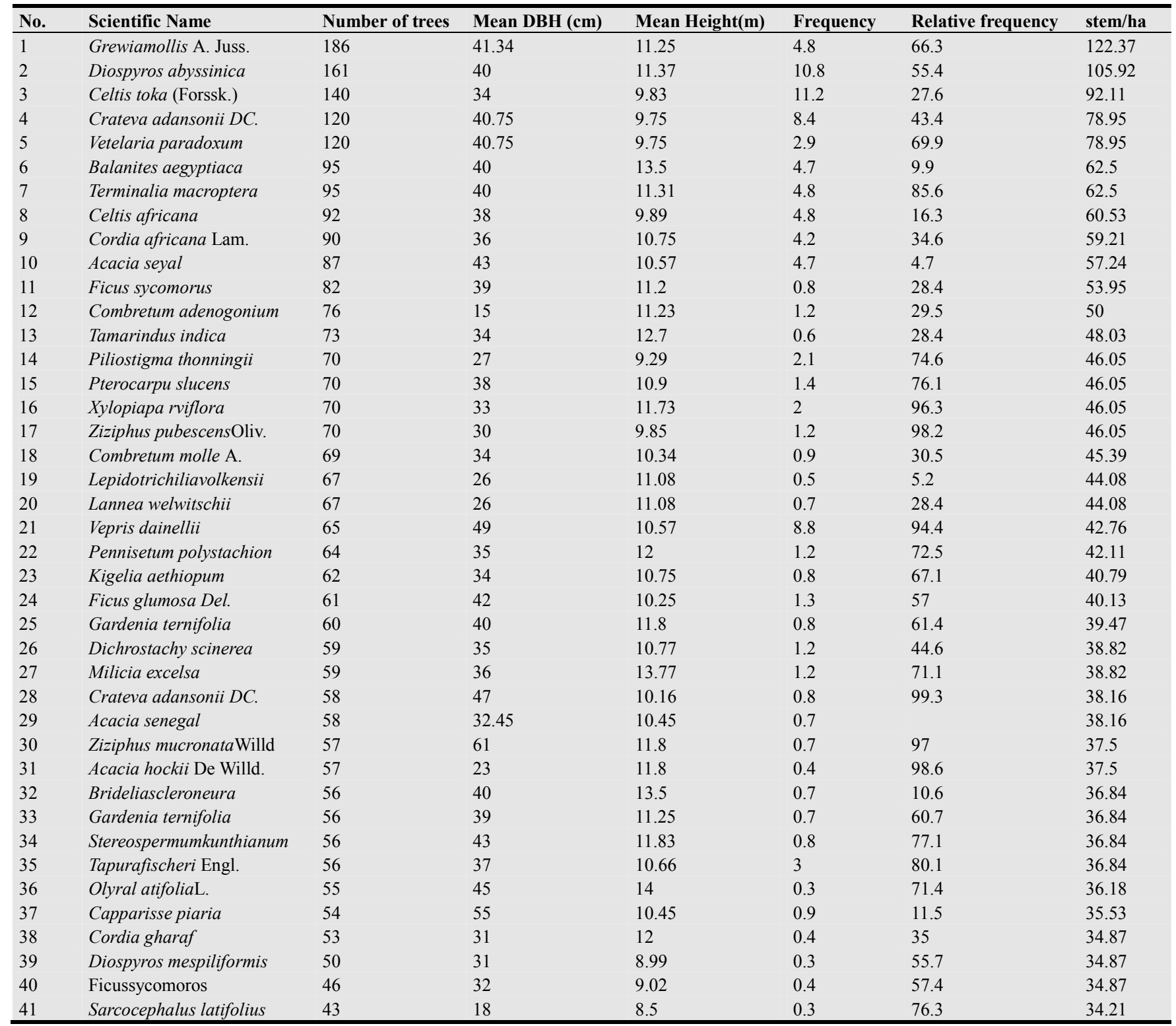

\section{References}

[1] Gebere Markos Woldie Selassie (999) Gambella Forestry Action Program, Regional Bureau of Agriculture and Natural Resources, Gambella.

[2] Gurney KR, Raymond L. 2008. Targeting deforestation rates in climate change policy: a "Preservation Pathway" approach. Carbon Balance and Management.

[3] Mengistuwoube (1999) Flooding and sustainable land-water management in the lower Baro-Akobo riverbasin, Ethiopia. Applied Geography 19, 235-251 (FDPPA, 2007).

[4] EWCA (2008) The Value of the Ethiopian Protected Area System: Message to Policy Makers. Addis Ababa, Ethiopia.
[5] Kent M, and Coker P (1992) Vegetation Description and Analysis. A practical approach. Bolhaven Printing Press, London.

[6] Pearson, T. R., Walker, S., and Brown, S. 2005. Sourcebook for land-use, land-use change and forestry projects. Winrock International and the Bio-carbon fund of the World Bank. Arlington, USA, pp. 19-35.

[7] Hedberg, Edwards (1989) Flora of Ethiopia. Vol. 3. Pittosporaceae to Araliaceae. Addis Ababa and Asmara, Ethiopia \& Uppsala, Sweden.

[8] Sheikh M A, Kumar M, Rainer W, and Bussmann R W (2009) Altitudinal variation in soil organic carbon stock in coniferous subtropical and broadleaf temperate forests in Garhwal Himalaya. Department of Forestry, HNB Garhwal University, Srinagar Garhwal, Uttarakhand, India. Carbon Balance management 4: 1-6. 
[9] NAHI (Natural Harness initiative) (2009) Baseline Survey for Rushebeya-Kanyabaha wetland landscape and Wambabyariverline forests System. Draft report submitted to Pro-Poor Rewards for Environmental Services in Africa (PRESA) Project, The World Agro- forestry Centre.

[10] EPA (2007) Ethiopia Environment Outlook, Environment for Development Addis Ababa, Ethiopia.

[11] Friis I (1992) Forest and Forest Trees of Northeast Tropical Africa. Their Natural Habitats and Distribution Patterns in Ethiopia, Djibouti and Somalia.
[12] Woldesemayat Alemu (2007) Land use/land cover changes environmental analysis and implication for sustainable agriculture development in Gambella Woreda, Gambella region south western Ethiopia. MSC thesis, aids Ababa University, Aids Ababa, Ethiopia.

[13] James Young (2012) Ethiopian Protected Areas A Snapshot, A Reference Guide. For Future Strategic Planning and Project Funding. Addis ababa, Ethiopia. 